\title{
The Habitat and Behavioural Environment of Onchocerciasis in Patigi Local Government Area, Kwara State, Nigeria
}

\section{Abstract}

\author{
Oye Babatimehi*
}

\begin{abstract}
Although onchocerciasis constitutes a major public health problem in rural Nigeria, the physical and behavioural environment of the disease needs to be adequately studied. The paper examines the physical and socio-economic factors of vulnerability to onchocerciasis in Patigi LGA, Kwara State, Nigeria. Topographical maps and published epidemiological reports are used to analyse people's proximity to vector breeding sites and the disease prevalence respectively. Regression is the major analytical tool. Data show that, the physical environment particularly the water channels which on the average are 388 metres from the villages, as opposed to the vector's flight capacity of over 12 kilometres from the breeding point, provide the conducive breeding condition for the disease vector. Socio-economic characteristics of the people such as occupation (farming $85 \%$ and fishing 2\%); isolated and dispersed settlement patterns; and dressing pattern expose them to the disease vector bite. Regression analysis shows that there is significant relationship between population size and incidence of onchocerciasis $(P<.001)$. The number of people infected has a direct relationship with population $(P<.001)$, while the intensity of the disease is inversely related to population $(P<.05)$. In conclusion, the study shows that both physical and socio-economic factors determine vulnerability to onchocerciasis. Therefore, onchocerciasis control efforts and rural development planning programme should reflect spatial peculiarities accompanied by public enlightenment campaign on the vulnerability factors.
\end{abstract}

Key words: Onchocerciasis, Physical environment, Socio-economic environment, Vulnerability, Patigi LGA

\section{Introduction}

$\mathrm{O}_{\text {known as river blindness is }}^{\text {nchocerciasis, }}$ one of the world's major endemic parasitic diseases which affects the eye and can lead to blindness when it reaches an advanced stage in the human body (Edungbola, 1991; Lieze et al, 1991). Onchocerciasis causes extensive skin disfiguration associated in some cases with severe discomfort. The skin manifestations of onchocerciasis are often characterised by dermatitis, thickening and atrophy of the skin and pigmentry aberrations such as leopard skin. Other debilitations of the disease include hanging groin and scrotal elephantiasis (WHO, 1988; Edungbola, 1991). Apart from its effects on the human body, onchocerciasis has often been indicted for the devastation and decay of communities where it is endemic (WHO, 1988; Edungbola, 1991).

About 17.6 million people all over the world are infected with the disease, out of which one million are totally or partially blind (WHO, 1995). More than 95 per cent of onchocerciasis infected persons are in Africa (Umen et al, 1996), and Nigeria is the most endemic country in the world, harbouring about 60 per cent of all onchocerciasis cases in West Africa (WHO, 1987) and 30 to 40 per cent of all cases in the world (Carter Centre, 1995). The National Onchocerciasis Control Programme (1993) reported that the disease is present at varying degrees in all states of the federation. And over 15 thousand Nigerian rural communities are endemic to the disease Pond (1995).

In Kwara State, Edungbola (1982) reported an average prevalence rate of about 64 per cent in the rural communities.

\footnotetext{
*Department of Geography,Obafemi Awolowo University,Ile-Ife, Nigeria. oyebabatimehin@yahoo.com Acknowledgements -The author is grateful to Professor S.I. Okafor and Dr. D.D. Ajayi for supervising the study on which this paper is based.
} 
Particularly, a prevalence rate of about 68 per cent has been reported in Patigi area (Edungbola, 1982 and Africare, 1991),

thus, making the area one of the most endemic part of Kwara State.

In fact, 100 per cent prevalence was recorded in some communities in Patigi area of the state. The fact that Nigeria is the most onchocerciasis endemic country in the world has prompted the Federal Ministry of Health in the country to embark on control measures (Gyoh, 1993). Sequel to government's intervention, the United Nations agencies (WHO, UNICEF), international and local non-governmental agencies, state and local governments have embarked on programmes aimed at controlling river blindness in Nigeria.

Although, the pathological and entomological aspects of onchocerciasis have been widely studied, the ecological and behavioural factors that determine the occurrence and vulnerability to the disease in specific localities have received little attention in the literature. Onchocerciasis is both a behavioural and a medical problem. The physical and socioeconomic environment of people at risk of infection must be understood in any meaningful study of the disease. While the physical environment provides the enabling condition for the disease vector to breed, social and economic factors influence people's choice of residential site. Such decisions may, in turn, affect their exposure to onchocerciasis. People might be ignorant of the danger of locating homes and even economic activities near river valleys that are infested with simulium damnosum (the disease vector) and associated onchocerca-volvulus (disease parasite). When they do, the perceived economic gains may far outweigh the perceived loss from contracting onchocerciasis. Also, while the simulium flies are generally recognised for constituting biting nuisance both at home and at work, their ability to transmit onchocerciasis may not be appreciated by affected individuals and communities. In some cases, people might be ignorant of the causal relationship that exists among the various ailments associated with the disease.

In order to broaden our knowledge of the disease endemicity, it is pertinent to understand the physical and behavioural factors that enhance people's vulnerability to the disease. This paper, therefore, analyses the physical and behavioural factors of onchocerciasis prevalence in the endemic area of Patigi, Kwara State, Nigeria.

The paper hypothesises that, the incidence of onchocerciasis is a function of population and distance of place of residence to disease vector breeding site.

\section{Study Area}

Patigi Local Government Area (LGA), Kwara State, Nigeria, constitutes the study area. The LGA is located within Latitudes $8^{\circ} 30^{\prime} \mathrm{N}$ and $8^{\circ} 57^{\prime} \mathrm{N}$ and longitudes $5^{\circ} 30^{\prime} \mathrm{E}$ and $6^{\circ} 11^{\prime} \mathrm{E}$. The LGA is one of the 16 in the State (see Figure 1). Patigi LGA is endemic to onchocerciasis. The black fly, simulium damnosum that transmits the disease parasite (onchocercavolvulus) in the study area breeds mainly along the Kampe River and its numerous tributaries, and also along the other rivers and gullies (Edungbola, 1982; Africare, 1991). The River is one of the numerous tributaries to River Niger, it stretches from Apata Hill in Ekiti State, through territories of Okun land, Kogi State and Nupe land, Kwara State, and finally joins River Niger at Eggan in Niger State.

\section{Methodology Sampling}

Multi-stage sampling was employed in this study for collection of data from the primary source. Patigi Local Government Area was stratified into the three existing administrative districts Lade, Patigi and Kpada. From each stratum, 200 respondents were selected using the LGA's Onchocerciasis Control household register as the database. The list has a total of 3005 registered households, out of which 600 households (representing about 20 per cent) were sampled. The households interviewed were selected using the random sampling technique. The questionnaire interview was conducted at household level; while 
the head of each household was interviewed.

\section{Data collection procedure Primary data}

The questionnaire administered on 600 randomly selected respondents in the study area served as the basic tool for collecting data from the primary source. Basically, the questionnaire pertains to the location and demographic characteristics (age, sex, level of education and occupation) of respondents.

\section{Secondary data}

Topographical maps and other available maps of the study area that show the drainage system and the spatial distribution of human activities, provided information on the distances of the various communities from the disease vector breeding sites (along the rivers channels). Africare (a non-governmental organisation which was saddled with the responsibility of controlling onchocerciasis in Kwara State, but later transferred to APOC), was working in collaboration with the Kwara State Ministry of Health to control the disease in the state. At the commencement of its operation in Kwara State, the agency conducted an epidemiological survey of the disease (using skin snipping method) in selected communities in the state. Furthermore, Edungbola (1982) reported the result of an epidemiological survey of the disease in rural communities in Kwara State. The study involved the skin snipping of 14,589 randomly selected persons in all the LGAs in the state. The result shows that about 64 per cent of the sampled population had the disease microfilariae in their body. The results of these studies were used to analyse the prevalence of the disease in the study area.

\section{Discussion}

The physical environment of onchocerciasis in Patigi area

The relationship between man and his environment is symbiotic. Although, it is generally believed that the environment influences human activities, these activities in turn influence the nature of the environment. Physical, social and economic factors are very important factors that determine the severity of onchocerciasis in any given society. The numerous rivers and gullies in the study area provide favourable breeding sites for the disease vector (Edungbola, 1982; Africare, 1991; Kwara State Ministry of Health, 1992) (see Figure 2).

Table 1 provides the distance of various communities to the river channel that is nearest to them, while Figure 1 shows the drainage system in Patigi LGA. It is shown that most villages are very proximate to streams and rivers that serve as breeding sites for the disease vector. Indeed, quite a number of villages are located right at the bank of river channels. Ndanaku which is located about two kilometres from a river is the farthest village to a river in the whole LGA. This is followed by Gudugi and Gbado-Pati which are about 1.3 kilometres and 1.2 kilometres respectively from the nearest river. On the average the communities in the study area are located in less than 400 metres from the streams and rivers. Given the close proximity of settlements to river channels, Patigi LGA is expected to be highly endemic to onchocerciasis. This is especially so when one considers the fact that the simulium fly has a flight range of about 12 miles. This could be more when assisted by wind. An average distance of less than one kilometre to the simulium fly breeding sites portends that the disease vector would be widely dispersed in the area, because no community falls outside the range of vector dispersal.

The distances presented in Table lare those of each of the communities to the nearest river. There could be other rivers around the communities that also serve as breeding sites for the simulium fly. Erosion rills and gullies which are common features of settled areas (ovi) create suitable (position sites for the simulium fly in the rainy season, thus breeding may not be confined to the streams and river channels only. Given the drainage system in the area which provides abundant breeding sites for the disease vector, the high prevalence of the disease in the area is therefore not unexpected.

The socio economic environment of onchocerciasis in Patigi area

Although, the physical environment provides the conducive 
breeding condition for the disease vector, the nature of social and economic activities determine the level of contact with the fly and therefore the intensity of bites received by an individual at any point in time. Onchocerciasis is a disease of rural communities. Studies have shown that onchocerciasis is more common among farmers, fishermen, hunters, normads and others who are engaged in outdoor activities that brings them in constant contact with the simulium fly (Edungbola, 1982).

The socio-economic (behavioural) environment of onchocerciasis discussed here pertains to the inhabitant's occupational characteristics, dressing habits, and settlement pattern. Table 2 show that whereas, 511 (85 per cent) respondents are farmers, 11 ( 2.7 per cent) and 14 (2.3 per cent) are engaged in trading and fishing respectively. Only 4 ( 0.7 per cent) respondents are into hunting and herding respectively. A total of 51 (8.5 per cent) are in other occupations which include the civil service (majority of whom are primary school teachers and local government workers) and quranic teaching. It should be noted however, that like in many other rural communities, most people in the area are engaged in farming regardless of their primary occupation.

Figure 3 show that all respondents who are hunters and herdsmen have onchocerciasis, while 15 out of 16 traders (representing 94 per cent) have the disease. A total of 359 (70.3 per cent) farmers are infected with onchocerciasis, while the least prevalence is recorded among the fishing group where 6 out of 14 (46 per cent) respondents are infected with the disease.

Another important factor in the transmission of onchocerciasis is people's mode of dressing. Given the mode of transmission of onchocerciasis, it would be expected that people in this endemic area would always wear protective clothing especially during the period they engage in onchocerciasis risk activities. However, it was observed that no extra effort is made by inhabitants of these communities to ward off the flies. Naked children and women with parts of their body exposed, go to the streams to perform domestic activities such as washing and fetching water. Also, occasions may demand that adults are naked to the waist when they engage in farming and fishing, thereby exposing themselves to the fly bite.

The size of communities in areas of heavy transmission of onchocerciasis is an important determinant of the transmission and severity of complications. The fewer the people in an area, the higher the number of bites that are received per person and thus the higher the individuals' parasite load. However, when a community is inhabited by a large number of people, the fly bite will be spread over a large number of people thus the intensity of bites that are received per person will be reduced.

Although, the relationship between the volume of infection with onchocerciasis and population may be direct, it is evident that places with the lowest population have the highest prevalence rates. Table 3 shows that sparsely populated villages like Shiaagi (150 inhabitants) and Yagbagi (200 inhabitants) have 100 per cent prevalence rates respectively. While the relatively densely populated communities like Kpada (4000 inhabitants), Edogi (1000 inhabitants) and Sheshi-Tasha (900 inhabitants) have the least prevalence rates of $41.9,42$ and 50 per cent respectively. All villages with population above 350 people have prevalence rate below the overall average (67 per cent) except Koro which though has a population of 1650 , has a prevalence rate of 77.1 per cent. Table 4 presents the physical and socioeconomic (behavioural) factors of vulnerability to onchocerciasis.

Disease occurrence in human society is normally influenced by environmental factors which include both the physical and behavioural environments. Meade, et al., (1988) note that the complex system of interaction among the physical environment, population and cultural behaviour forms the triangle model of human ecology and forms the basis of disease occurrence in 
human population. In this study, people's proximity to rivers which serves as breeding site for simulium damnosum constitute an indicator of the man-fly contact which is a very important factor in the transmission of onchocerciasis (Hunter, 1980). Another important factor in the prevalence of onchocerciasis is the human population relative to fly population (Prost, 1989), which is also an important indicator of the man-fly contact. Due to the importance of rivers and population size in man-fly contact, and the prevalence of onchocerciasis (see literature), it could therefore, be hypothesised that the incidence of onchocerciasis is a function of population and proximity to disease vector breeding site. This hypothesis will help us to ascertain the extent to which these factors explain the disease prevalence.

In order to ascertain the role of physical and socio-economic factors in the prevalence of onchocerciasis in the study area, the regression analysis was carried out. The number of people infected with onchocerciasis in the various communities' serves as the dependent variable, while the population size and the distance of communities to the nearest river constitutes the independent variables (See Table 3).

The regression model is given as:

$$
Y=a+b_{1} X_{1}+b_{2} X_{2}+e
$$

Where $Y$ is number of people infected with the onchocerciasis in each community; $\mathrm{X}_{1}$ is population in each community; $\mathrm{X}_{2}$ is distance of each community to the nearest river respectively; a is base constant; $b$ is regression coefficient; e is error term.

The result of the regression analysis in Table 5 shows that of the two independent variables, population alone significantly influence the number of people infected with onchocerciasis in the study area. This is so given the fact that the population factor has $\mathrm{R}=0.956 ; \mathrm{R}^{2}=$ 0.913; and Adjusted $\mathrm{R}^{2}=0.909$. Furthermore, the $\mathrm{F}$ value is 231.393 and this is significant at 1 per cent level. This implies that the population factor explains 91.3 per cent of onchocerciasis occurrence in the study area. However, population is shown to have a positive coefficient $(0.457)$ with onchocerciasis occurrence.

When the dependent variable is substituted with the proportion of the population infected with onchocerciasis, the result shows that the population factor has $\mathrm{R}=0.408, \mathrm{R}^{2}=0.167$ and Adjusted $\mathrm{R}^{2}$ $=0.129$. The "F" value is 4.395. This is significant at 5 per cent level. The regression coefficient is shown to be negative (-0.0078) (see Table 6 and Figure $5)$. This result implies that the proportion of people infected with onchocerciasis is inversely related to population.

The results show that while the number of people infected with onchocerciasis in a given community may increase with increasing population, the proportion of the population infected with onchocerciasis decreases with increasing population.

The result shows that distance of place of residence to disease vector breeding site is not a significant factor of onchocerciasis prevalence. One important factor that appears to account for the insignificance of distance in onchocerciasis prevalence is the vectors flight range of about 12 miles radius from the breeding point. This relative to the communities average distance of about 0.4 kilometre to vector breeding sites appear to put the entire communities within effective reach of the vector and thus renders the importance of distance on the reach of the vector insignificant.

\section{Summary and conclusions}

Data show that, the physical environment particularly the water channels which on the average are 388 metres from the villages as opposed to the vector's flight capacity of over 12 kilometres from the breeding point, provide the conducive breeding condition for the disease vector. Socio-economic characteristics of the people such as occupation (farming $85 \%$ and fishing 2\%); isolated and dispersed settlement patterns; and dressing pattern expose them to the disease vector bite. Regression analysis shows that there is significant relationship between population size and incidence of onchocerciasis $(\mathrm{P}<.001)$. The number of people infected has a direct relationship with population $(\mathrm{P}<.001)$, while the 
intensity of the disease is inversely related to population $(\mathrm{P}<.05)$.

The assumption that all the rivers in the study area serves as breeding point for the disease vector may not be true after all. There is the need to ascertain the specific rivers and streams that serve as breeding site for the simulium fly. The regression analyses have shown that the intensity of the disease in any given population is inversely related to its

\section{REFERENCES}

Africare (1991), Kwara State blindness prevention programme: summary of project activities. Africare, Kwara State.

Carter Center (1995), Summary proceedings: program review of Nigerian Onchcerciasis Control Program. Carter Centre, Lagos.

Edungbola, L.D. (1982), Onchocerciasis in Kwara State, Nigeria. Proceedings of the First National Conference on Onchocerciasis. NITR, Kaduna, Nigeria. Edungbola, L.D. (1991), Onchocerciasis control in Nigeria. Parasitology Today, 7 (5), 97-99

Edungbola, L.D. et al., (1991), Hernias and onchocerciasis. The Nigerian Journal of Parasitology, 12, 45-50.

Gyoh, S.K. (1993), National plan of action for the control of onchocerciasis (River Blindness) in Nigeria. Federal Ministry of Health, Lagos.

Hunter, J.M. (1980), "Strategies for the control of river blindness". In M.S.

Meade (ed), Conceptual and Methodological Issues in Medical Geography, Department of Geography, University of Carolina, pp. 38-76.

International Labour Organisation, (1979), Man in his working environment. International Labour Organisation, Geneva.

Kwara State Ministry of Health (1992), Prevalence of skin microfilarae by villages and sex of subjects in 43 villages in Edu LGA. Kwara State Ministry of Health, Ilorin. population. However, caution must be exercised to ensure that this assertion is made correctly because it has been shown that while intensity of onchocerciasis is inversely related to population, the actual number of people infected with the disease is directly related to population. We can therefore conclude that one of the main reasons for the high prevalence of onchocerciaisis in Patigi area is the relatively sparse population.

Lieze, et al., (1991), "Onchocerciasis control programme in West Africa". In Population and Human Resources, Health Services Department, World Bank, Washington, D.C.

Meade, M. Florin, J. and Gesler, W (1988), "The human ecology of disease". In Meade, M. et al., (eds), Medical Geography, The Guilford Press, New York, pp. 29-54.

National Onchocerciasis Control Programme (1993), National plan of action for the control of onchocerciasis(River Blindness) in Nigeria. Federal Ministry of Health and Social Services, Lagos.

Pond, R. (1990), Mass distribution of ivermectin: A handbook for community treatment of onchocerciasis. Africare / IEF, Washington DC.

Prost, A. (1989), "Socio-economic environment of onchocerciasis". In Miller, M.J. and E.J. Love (eds.) Diseases: Treatment and Control, CRS Press Incorporation. Florida, U.S.A. pp.176-178. WHO (1987), Third report on the WHO expert committee on onchocerciasis. WHO Technical Report Series 752. World Health Organisation, Geneva.

WHO (1988), Report of the first round ivermectin treatment. World Health Organisation, Geneva.

WHO (1995), Onchocerciasis and its control: report of WHO expert committee on onchocerciasis control. WHO Technical Report Series, No. 852. 
Table 1: Villages in Patigi LGA and distance from river/stream

\begin{tabular}{|c|c|c|c|}
\hline Village & $\begin{array}{l}\text { Distance to nearest } \\
\text { river (Metre) }\end{array}$ & Village & $\begin{array}{l}\text { Distance to nearest } \\
\text { river (Metre) }\end{array}$ \\
\hline Raniworo & 200 & Yagbagi & 1000 \\
\hline Rani Ramat & 200 & Katsa & 300 \\
\hline Rani Ndako & 450 & Gbagafu & 600 \\
\hline Salepetu & 10 & Suku & 200 \\
\hline Bisan & 400 & Koro & 250 \\
\hline Chanagi & 890 & Dagbalodo & 30 \\
\hline Magya & 150 & Kasita & 100 \\
\hline Dzwajiwo & 150 & Jida & 200 \\
\hline Bongi & 200 & Sokingi & 150 \\
\hline Kakafu & 400 & Kpada & 100 \\
\hline Gbodonji & 180 & Mashia & 100 \\
\hline Ekati & 200 & Gakpan & 20 \\
\hline Dina & 350 & Duro & 400 \\
\hline Mari & 450 & Tebu & 250 \\
\hline Ndanaku & 2000 & Reshe & 150 \\
\hline Gadaworo & 200 & Wodatai & 500 \\
\hline Gada Bozuwo & 30 & Agboro & 400 \\
\hline Lile & 20 & Labongi & 100 \\
\hline Gada Ndako & 10 & Emigi & 700 \\
\hline Gada Masin & 200 & Kusogi & 200 \\
\hline Chitta & 150 & Gasefu & 750 \\
\hline Esanti & 900 & Godiwa & 800 \\
\hline Wodata & 1000 & Kparumagi & 800 \\
\hline Kanworo & 450 & Gudugi & 1300 \\
\hline Eka cheta & 10 & Lagada & 1100 \\
\hline Eka Kuso & 10 & Likofu & 600 \\
\hline Guluka & 70 & Kkpotua & 20 \\
\hline Dzuruta & 70 & Sheshi Tasha & 450 \\
\hline Maagi & 200 & Gbara dogi & 900 \\
\hline Gulugi & 790 & Chiakiagi & 10 \\
\hline Wako & 450 & Gbadopati & 1200 \\
\hline Lusama & 800 & Esungi & 900 \\
\hline Zhituala & 10 & Gbadokin & 1190 \\
\hline Dobo & 800 & Lazi Yissa & 250 \\
\hline Saaci & 250 & Galogi & 250 \\
\hline Latayi & 200 & Edogi & 10 \\
\hline Namba & 300 & Koshi & 300 \\
\hline Shiaagi & 150 & Nimbo & 650 \\
\hline Rogun & 300 & & \\
\hline
\end{tabular}

Source: Computed based on Measurement from Topographical Maps 
Table 2: Occupational characteristics of respondents

\begin{tabular}{|l|c|c|}
\hline Occupation & Number of Respondents & Percentage Respondents \\
\hline Farming & 511 & 85.1 \\
Fishing & 14 & 2.3 \\
Hunting & 4 & 0.7 \\
Herding & 4 & 0.7 \\
Trading & 16 & 2.7 \\
Others & 51 & 8.5 \\
\hline Total & $\mathbf{6 0 0}$ & $\mathbf{1 0 0}$ \\
\hline
\end{tabular}

Source: Field Survey, 2000

Table 3: Population, prevalence and distance of selected communities from river/stream

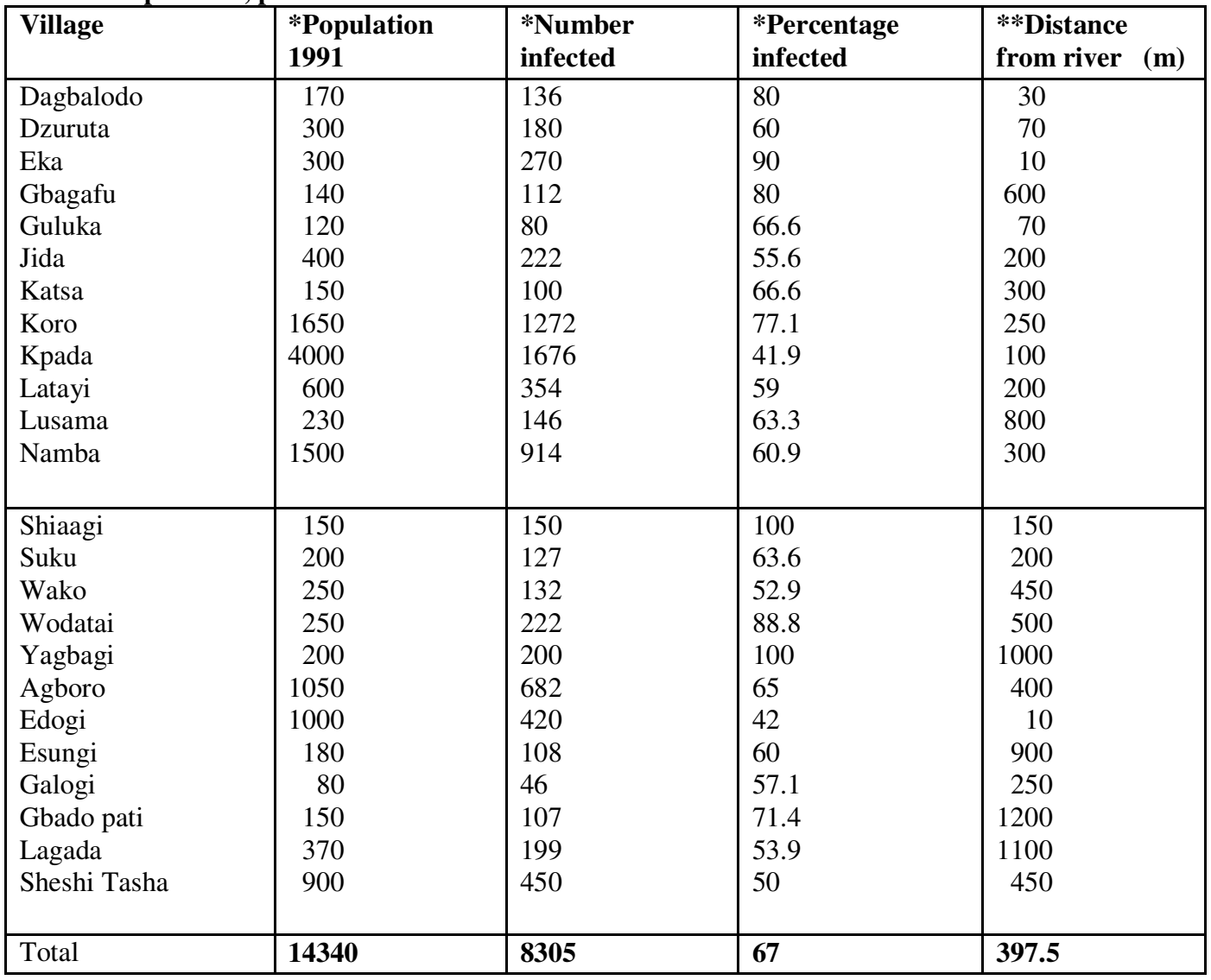

Source: *Africare 1991 **Topographical Map 
Table 4: Risk factors of onchocerciasis and their relevance to prevalence

\begin{tabular}{|l|l|}
\hline Risk Factor & Relevance to Disease \\
\hline SOCIO-ECONOMIC/ & \\
BEHAVIOURAL FACTORS & \\
Farming & Increase man-vector contact \\
Fishing & Increase man-vector contact \\
Hunting & Increase man-vector contact \\
Teaching & Reduce man-vector contact \\
Office jobs & Reduce man-vector contact \\
Water Supply & \\
Stream/River & Increase man-vector contact \\
Bore hole/Well & Reduce man-vector contact \\
Dressing & \\
Protective clothing & Limit exposure of body areas to vector bite \\
Non protective clothing & Increase exposure of body area to vector bite \\
Population & \\
High population density & Reduce intensity of vector bite received per person \\
Low population density & Increase intensity of vector bite received per person \\
PUBLIC HEALTH & \\
Drug & Increase breeding site \\
Dissemination of information & Decrease microfilariae load limits infection \\
Vector control & Reduced high risk behaviour reduces man-vector contact \\
PHYSICAL FACTORS & Decrease breeding site \\
Streams/Rivers & \\
Gullies & \\
Dams & \\
\hline
\end{tabular}

Source: Adapted from Ngare and Lamounier, 1989

Table 5: Summary of the regression analysis

\begin{tabular}{lc}
\hline R & 0.956 \\
R Square & 0.913 \\
Adjusted R Square & 0.909 \\
Standard Error of the Estimate & 122.26 \\
Coefficient & 0.457 \\
Degrees of Freedom & 23 \\
F - Ratio & 231.393 \\
Probability of Chance & 0.000
\end{tabular}

Source: Computed 
Table 6: Summary of regression analysis

$\begin{array}{ll}\text { R } & \mathbf{0 . 4 0 8} \\ \text { R Square } & 0.167 \\ \text { Adjusted R Square } & 0.129 \\ \text { Standard Error of the Estimate } & 15.0927 \\ \text { Coefficient } & -0.0078 \\ \text { Degrees of Freedom } & 23 \\ \text { F - Ratio } & 4.395 \\ \text { Probability of Chance } & 0.048\end{array}$

Source: Computed

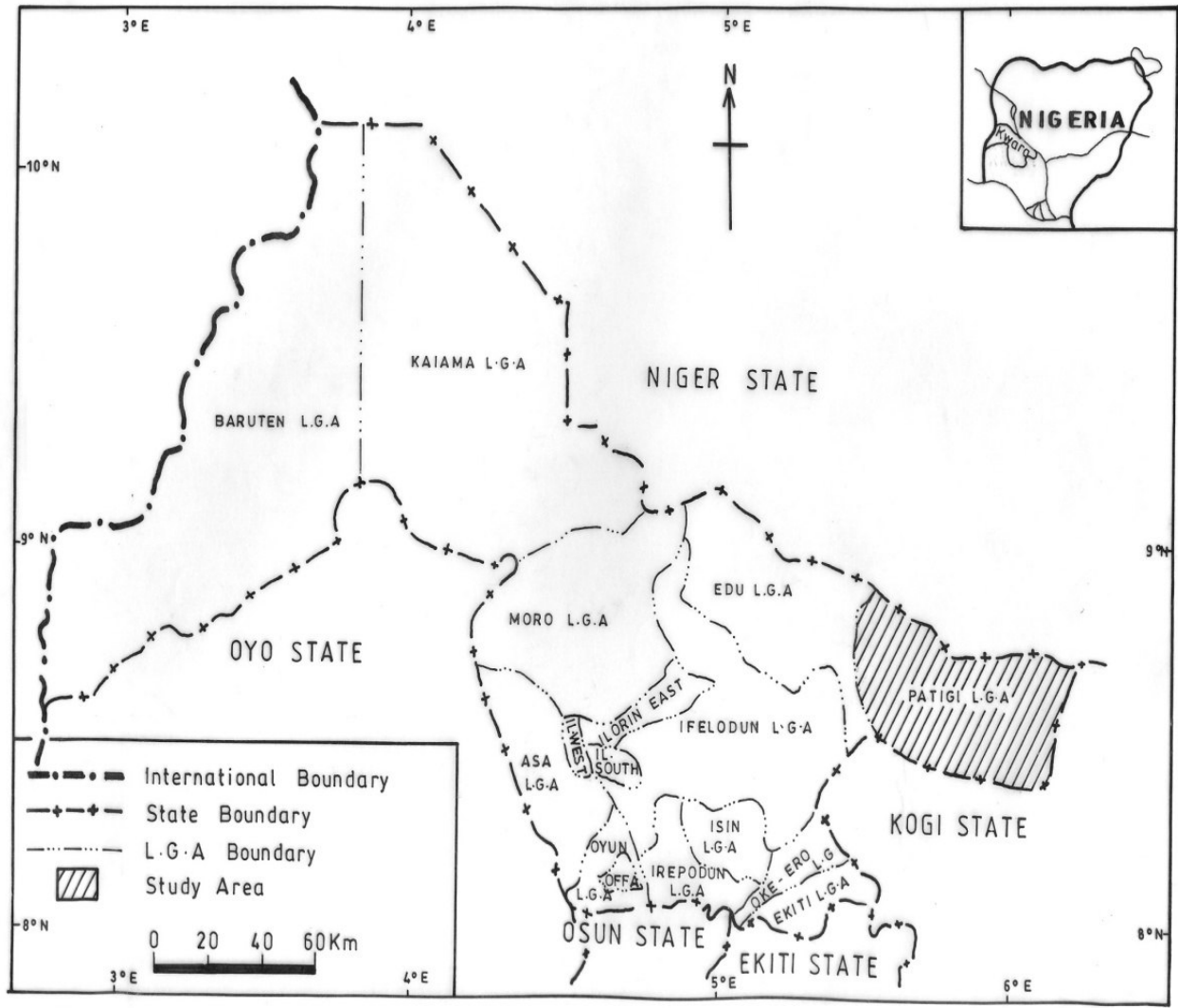

Fig. Kwara State Showing Patigi LGA

Source: Ministry of Information Kwara State Secretariat. 


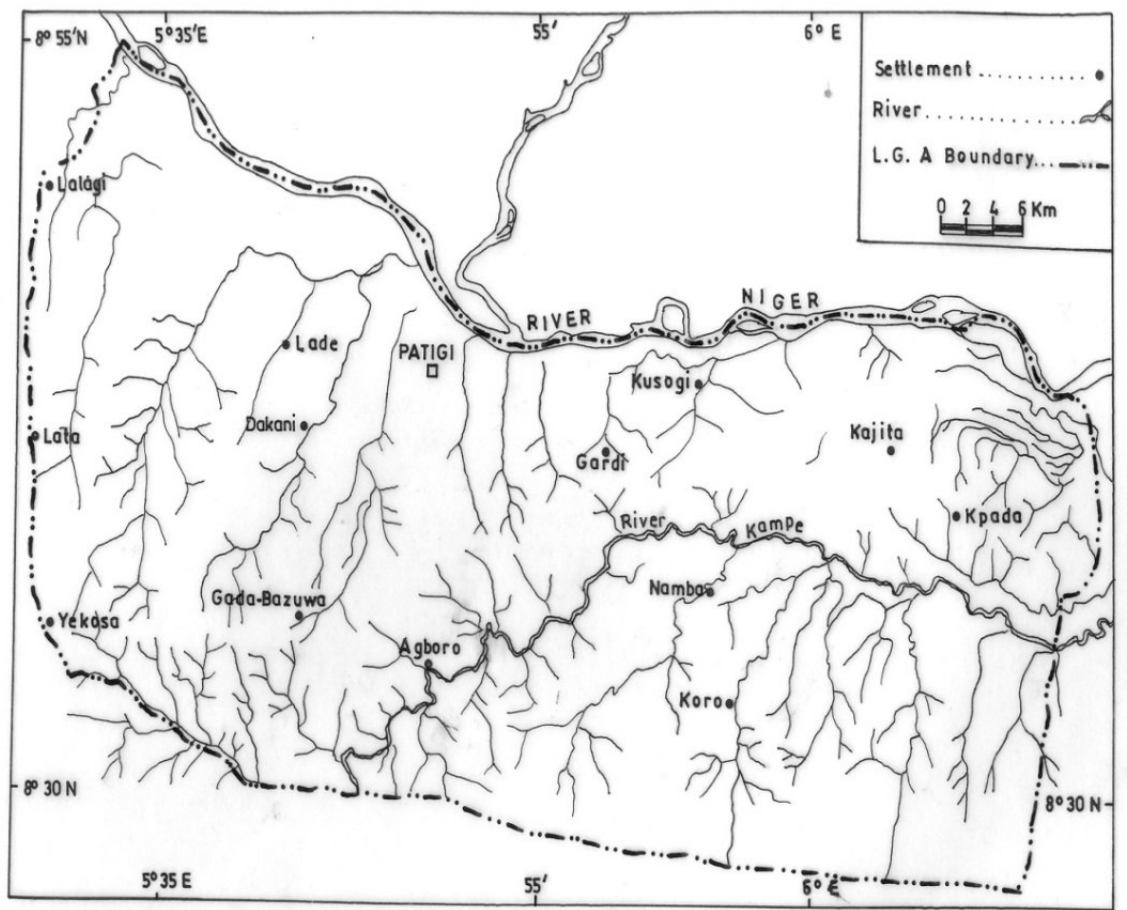

Fig. : Drainage System of Patigi L.G.A

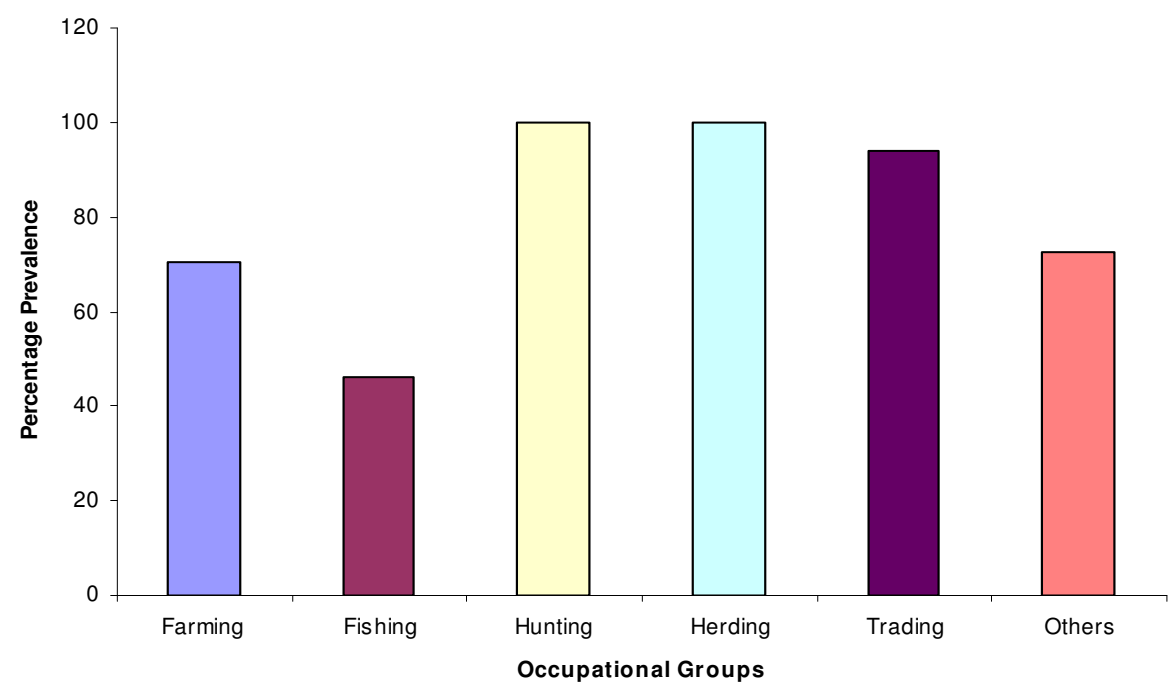

Fig. 3 Onchocerciasis Prevalence among Occupational Groups 


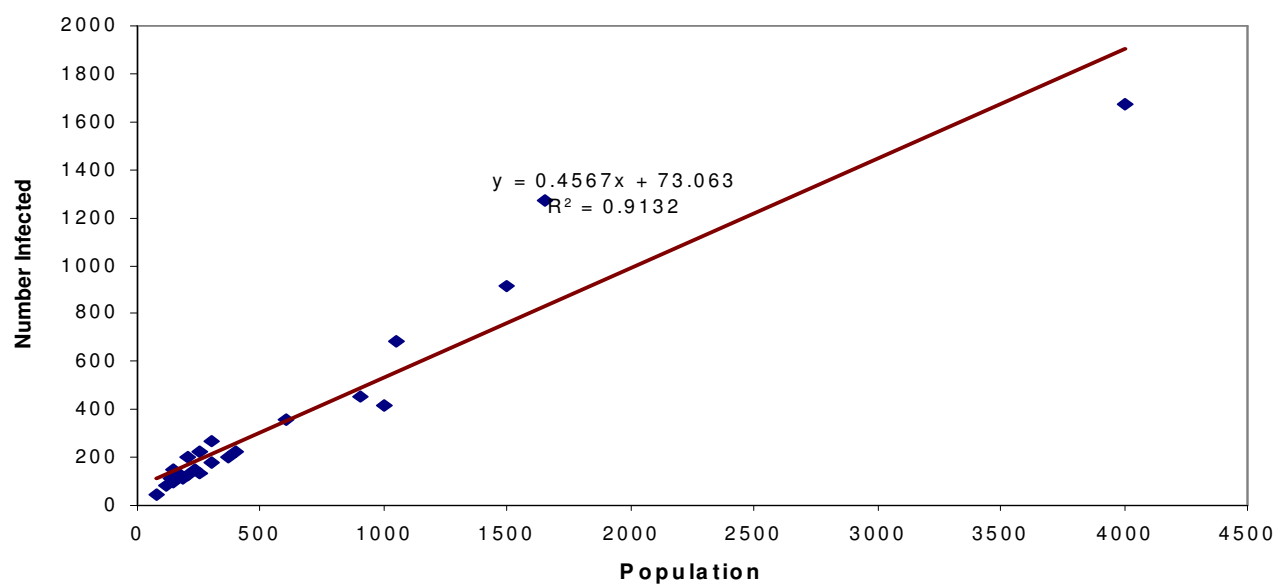

Fig. 4: Regression Curve

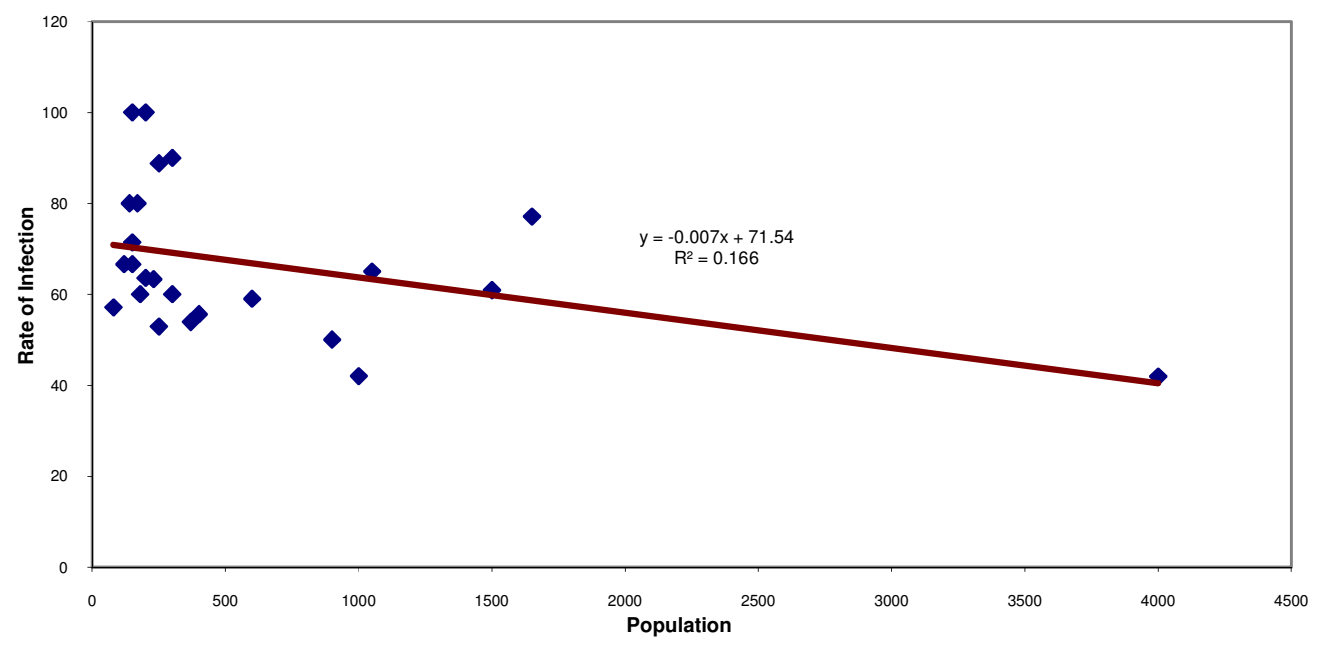

Fig. 5: Regression Curve 